\title{
enigma da constituição subjetiva no autismo: uma leitura psicanalítica da autobiografia de Temple Grandin
}

\author{
The enigma of the subjective constitution in autism: \\ A psychoanalytical analysis of Temple Grandin's autobiography
}

\author{
Mayara Yasmim Pinto Borges', Maria Luiza Sarno Castro² \\ 'Escola Bahiana de Medicina e Saúde Pública. Salvador, Bahia, Brasil. ORCID: 0000-0003-2560-9122. mayaraborges14.1@bahiana.edu.br \\ ${ }^{2}$ Autora para correspondência. Escola Bahiana de Medicina e Saúde Pública. Salvador, Bahia, Brasil. \\ ORCID 0000-0001-8563-3787. luizasarno100@gmail.com
}

\begin{abstract}
RESUMO | Esta pesquisa tem como objetivo analisar a autobiografia de Temple Grandin, com base na teoria da alienação e separação elaborada no primeiro ensino de Lacan durante o Seminário 11. O estudo contou com o método qualitativo, a partir da análise documental do livro "Uma menina estranha: Autobiografia de uma autista". Os resultados da análise apontam que apesar de cada autor ter uma particular leitura do autismo, que ainda gera debates, eles convergem em alguns aspectos, como o diagnóstico diferencial do autismo e psicose e que na estruturação subjetiva da criança autista, o cerne da questão está no processo da alienação, sendo possível observar sinais do autismo desde a primeira infância. Concluindo que apesar de não haver uma melhor teoria a respeito do autismo, devendo se levar em consideração o caso a caso do paciente em questão, a análise da autobiografia de Temple Grandin aponta para a hipótese apresentada por Maleval da alienação parcial.
\end{abstract}

PALAVRAS-CHAVE: Autismo. Psicanálise. Alienação. Separação.

\begin{abstract}
I This research aims to analyze the autobiography of Temple Grandin, based on the theory of alienation and separation elaborated in the first teaching of Lacan during Seminar 11. The study relied on the qualitative method, from the documentary analysis of the book "A girl Strange: Autobiography of an Autistic ". The results of the analysis point out that although each author has a particular reading of autism, which still generates debates, they converge in some aspects, such as the differential diagnosis of autism and psychosis and that in the subjective structuring of the autistic child, the heart of the matter is of alienation, being possible to observe signs of autism from the early childhood. In conclusion, although there is no better theory about autism, considering case by case of the patient in question, the analysis of Temple Grandin's autobiography points to Maleval's hypothesis of partial alienation.
\end{abstract}

KEYWORDS: Autism. Psychoanalysis. Alienation. Separation. 


\section{Autismo da psiquiatria a psicanálise:} introduzindo a questão

Cada vez mais se fala de autismo sem saber muito bem o que é; o gosto pela solidão, sua fixidez e condutas estereotipadas aparecem em primeiro plano caracterizando um funcionamento subjetivo singular (Tendlarz, 2017). Contudo o termo autismo não é novo, este foi cunhado em 1906 por Plouller, enquanto estudava $\circ$ processo do pensamento de pacientes com diagnóstico de demência, entretanto, o nome só foi disseminado em 1911 pelo psiquiatra suiço Eugen Bleuler, que o apontou como um dos sintomas fundamentais da esquizofrenia. Bleuler tomou da teoria freudiana o termo autoerotismo e subtraiu Eros, indicando o autismo como efeito da dissociação e tentativa de adaptação ao processo patológico; uma ruptura das relações com o mundo exterior (Dias, 2015).

Leo Kanner, em 1943, é quem descreve pela primeira vez $\circ$ autismo em crianças na síndrome que se tornou célebre intitulada "Autismo infantil precoce". Ele observou nestas crianças respostas incomuns ao ambiente, que incluíam maneirismos motores estereotipados, resistência à mudança ou insistência na monotonia, bem como aspectos não-usuais das habilidades de comunicação da criança, tais como a inversão dos pronomes e a tendência ao eco na linguagem (ecolalia). Ele diz que as crianças agiam como se não estivesse ninguém ali, como se estivessem hipnotizadas, eram autossuficientes e ficavam felizes quando deixadas sozinhas (Kanner, 1943).

Poucos anos depois, Asperger cria a "Síndrome de Asperger" para nomear crianças também subtraídas do laço social, mas com maior habilidade discursiva (Tendlarz, 2017).

Durante os anos 1950 e 1960 houve um grande debate sobre a natureza do autismo e sua etiologia, sendo a crença mais comum a concepção de que o autismo era causado por pais não emocionalmente responsivos aos seus filhos (a hipótese da "mãe geladeira"). Entretanto, na maior parte do mundo, tais noções foram abandonadas. No início dos anos 1960, surge uma linha de pesquisa sobre o autismo que busca compreender as questões como um transtorno cerebral presente desde a infância e encontrado em todos os países e grupos socioeconômicos e étnico-raciais investigados (Klin, 2006).

Em 1978 o psicólogo Michael Rutter propõe uma definição do autismo com base em quatro critérios: 1) atraso e desvio sociais não só como função de retardo mental; 2) problemas de comunicação, novamente, não só em função de retardo mental associado; 3) comportamentos incomuns, tais como movimentos estereotipados e maneirismos; e 4) início antes dos 30 meses de idade. A definição de Rutter e o crescente corpo de trabalhos sobre o autismo influenciaram a definição desta condição na terceira versão do Manual Diagnóstico e Estatístico de Transtornos Mentais (DSM-III), em 1980, quando o autismo pela primeira vez foi reconhecido e colocado em uma nova classe de transtornos, a saber, os Transtornos Invasivos do Desenvolvimento (TIDs). Até então o autismo era classificado no DSM-I e no DSM-II, na rubrica "reação esquizofrênica ou esquizofrenia forma infantil" (Klin, 2006).

No DSM-IV o autismo continuou na seção Transtornos Invasivos do Desenvolvimento, que se caracterizava por prejuízo severo e invasivo em diversas áreas do desenvolvimento; esta mesma seção abarcava - Transtorno Autista, Transtorno de Rett, Transtorno Desintegrativo da Infância, Transtorno de Asperger e Transtorno Invasivo do Desenvolvimento SemOutra Especificação (American Psychiatric Association 2000).

Então no atual DSM-V tudo se aglutina no Transtorno do Espectro Autista. Considerado um transtorno do neurodesenvolvimento definido por um conjunto de condições que variam desde limitações muito específicas na aprendizagem ou no controle de funções executivas até prejuízos globais em habilidades sociais ou inteligência com início no período do desenvolvimento. Assim, o autismo é caracterizado por déficits persistentes na comunicação social e na interação social em múltiplos contextos, e presença de padrões restritos e repetitivos de comportamento, interesses ou atividades (American Psychiatric Association, 2014).

Percebe-se de tal modo que, o diagnóstico do DSM é essencialmente fenomenológico, pois têm como base os sintomas apresentados pelo indivíduo, 0 
que diferencia da psicanálise, que vai propor um diagnóstico estrutural, ou seja, operando através da transferência; não trabalha como um leitor de fenômenos e sim como nomeador de um modo de incidência do sujeito na linguagem. Seguindo essa vertente, se pensa o diagnóstico menos como uma descrição objetiva e mais como uma operação descritiva do analista, em que a nomeação da estrutura do paciente incide sobre a conduta do tratamento em vários níveis. Assim se acredita que dois sujeitos com estruturas subjetivas distintas podem apresentar sintomas semelhantes a depender das circunstâncias (Figueiredo \& Machado, 2000).

Quando se olha para o movimento psicanalítico, o autismo tem sua história despojada da conotação dada inicialmente por Freud com o autoerotismo. Bleuler situa no começo do século XX a introversão autista como uma modalidade da esquizofrenia, para descrever a retração do sujeito em relação ao seu entorno.

Enquanto isso, os pós-freudianos e os kleinianos começaram a se interessar por esse quadro. Melanie Klein localiza o caso do menino Dick dentro de uma esquizofrenia atípica. Nos anos 1950/1960, Margaret Mahler, coloca a necessidade de atravessar a carapaça autista. Francis Tustin postula a "carapaça autista" como uma barreira protetora frente ao mundo exterior, gerada pela auto sensualidade corporal que inclui o uso de objetos autistas e formas autistas de sensações. Durante a mesma época, Bruno Bettelheim, introduz a "fortaleza vazia". Nos anos 1970, Meltzer examina a topologia e o uso do espaço próprio, bidimensional, resultado da identificação adesiva. E do lado da orientação lacaniana, Rosine e Robert Lefort o pensam como uma quarta estrutura (Tendlarz, 2017).

Tendlarz (2017) em seu artigo "Lacan e o autismo em nossa época" retrata um panorama da relevância do ensino de Lacan na leitura do autismo. A autora traz que Lacan propriamente falou pouco sobre o autismo, já que o diagnóstico como tal não havia chegado ainda ao auge classificatório e midiático do século XXI. Entretanto, seu ensino oferece os contornos necessários para entender o autismo e propor uma direção do tratamento. Assim Lacan retoma o autismo entendido no sentido amplo em diversas oportunidades; como nos "Escritos técnicos de Freud" (1954), o caso Dick de Melanie Klein e o caso Robert, de Rosine Lefort. Em 1967, cerca de dez anos depois, comenta o caso de Martín der Sami Ali em sua "Alocução sobre as psicoses da criança" e, finalmente, volta a falar sobre o autismo em sua "Conferência em Genebra", de 1975. Tanto no caso Dick como em Robert, aponta como as crianças estão imersas no real. Quanto ao caso Martín, Lacan indica que, se o menino tampa seus ouvidos, é porque se protege do verbo e já está no pós-verbal.

Assim, se observa um interesse crescente da psicanálise com relação ao autismo, entretanto, alguns olhares e hipóteses ainda divergem entre si na atualidade. Alguns teóricos vão considerá-lo uma quarta estrutura (Jerusalinsky, 2012); outros entendem - autismo como uma recusa a resposta do Outro (Freire, 2002), sendo o Outro tomado como "o lugar em que se situa a cadeia do significante que comanda tudo que vai poder presentificar-se do sujeito" (Lacan, 1964/2008, p.200). Laznik (2013) e Catão (2015) defendem a hipótese que nos autistas ocorrem um fracasso no tempo de alienação da constituição do sujeito, pela impossibilidade ou recusa do remate do terceiro tempo do percurso pulsional. Outros autores vão propor que os autistas são sujeitos, mas não enunciadores, aparecendo como puro significado do Outro (Soler, 2007). Stefan (1991), por sua vez, situa $\circ$ autismo em um tempo anterior ao estádio do espelho, afirmando que no autismo não haveria Outro e sequer o outro, o semelhante. Ele defende que os autistas estão fora do discurso e fora da linguagem e sendo pela e na linguagem que se constitui o sujeito; no caso do autista haveria uma ausência de subjetivação. Em contrapartida, Maleval (2015) propõe que o autista não se situa na borda da alienação; ele está na alienação, mas a recusa. Assim uma das principais dificuldades quando se trabalha com crianças autistas é a diversidade de explicações que são dadas para $\circ$ autismo. A maioria dos neurologistas e mesmo uma grande parcela dos psiquiatras possuem uma compreensão que difere da dos psicólogos, e em especial dos psicanalistas. E mesmo dentro da própria psicanálise, como já foi mencionado, difere o entendimento sobre o que é o autismo, e assim, de acordo com cada forma de apreensão é que se pautam as práticas clínicas. 
A psicanálise lacaniana, a qual será abordada neste estudo, traz uma contribuição importante, situando o entendimento do autismo a partir da compreensão da constituição do sujeito. Esta teoria não nega as questões biológicas, as quais podem ou não existir, mas lança um novo olhar para o sujeito, para além do biológico, colocando a relação do infans com seu Outro no cerne da constituição subjetiva (Mexko \& Galhardi, 2014).

Considerando que para a psicanálise $\circ$ processo constituinte do sujeito não reside nem na satisfação nem na frustração de suas necessidades, nem tão pouco em um automatismo genético que garanta per se tal processo, mas que a operação que o situa, se define em outro nível: o do significante; é importante considerar as duas operações que se articulam na relação do sujeito com o Outro, denominado por Lacan como alienação e separação (Jerusalinsky, 2012).

\section{Alienação e separação}

A teoria lacaniana da alienação e separação se propõe explicar a constituição do sujeito a partir do significante, que são as palavras fundadoras, que envolvem $\circ$ sujeito, tudo aquilo que $\circ$ marca, seus pais, seus vizinhos, toda a estrutura da comunidade que o constitui não somente como símbolo, mas no seu ser (Jerusalinsky, 2012). Assim, a partir da alienação com o Outro (o tesouro dos significantes) emerge o sujeito que como tal só pode ser conhecido no lugar ou locus do Outro (Laurent, 1997). A teoria da alienação de Lacan (1964/2008) é apresentada por Bruder \& Braver (2007, p. 515):

A alienação é própria do sujeito; ele nasce por ação da linguagem. O lugar de Outro, que o cuidador ocupa neste momento, oferece significantes, através da fala; o sujeito se submete a um dentre os vários significantes que lhe são oferecidos. O seu ser não pode ser totalmente coberto pelo sentido dado pelo Outro: há sempre uma perda. Joga-se aí uma espécie de luta de vida e morte entre o ser e o sentido: se o sujeito escolhe o ser, perde o sentido, e se escolhe o sentido, perde o ser, e se produz a afânise, o desaparecimento do sujeito.
Assim a constituição do sujeito emerge por meio da alienação ao Outro detentor do sentido. Esse processo de alienação é correlato ao fato do encontro do indivíduo com a linguagem, que o precede, que aí estava antes de ele existir. Uma linguagem cujas regras e códigos estão já definidos, não tendo tido o sujeito nenhum papel em sua constituição. Essas leis Ihe são exteriores, e é preciso conformar-se a elas caso se queira obter o reconhecimento do Outro falante. Com efeito, será esse Outro que Ihe ensinará a servir-se da linguagem; Outro que fornecerá todos os significantes necessários a tal utilização (Nascimento, 2010).

Pode-se dizer que o encontro do indivíduo com o Outro se faz a partir da experiência de satisfação originária. É o Outro que coloca fim à tensão da necessidade. A criança vai registrar dessa experiência fundamental tanto os traços mnêmicos do objeto quanto as palavras pronunciadas na ocasião. Essa intervenção do Outro implicará a inserção da criança na ordem simbólica, ordem de troca de significantes. A primeira participação da criança nessa troca simbólica se faz através de seu grito, o qual se torna significante a partir do momento em que - Outro o acolhe como uma mensagem. É esse ato, essa resposta do Outro, o responsável pela "mutação significante" e o aparecimento do S1. Como afirma Nascimento (2010, p. 2):

Tem-se assim o par mínimo da cadeia significante: S1-S2. S1 como o substituto do grito, primeiro significante do sujeito; S2 como o significante da resposta do Outro, o significante que faz do grito mesmo um significante. Ora, dizer que é S2 que transforma, a posteriori, o grito em um significante, equivale a dizer que é S2 que inaugura a função propriamente de significação da linguagem. Em outros termos, não é senão após ter tido lugar a resposta do Outro que podemos realmente afirmar que houve algo como uma mensagem, um apelo. S2 é, portanto, o vetor semântico, já que é ele que dá, retroativamente, sentido a S1. A dimensão do sentido está assim na articulação de S1-S2. Dessa forma, não

é somente o fato de tomar $S 1$ como representante, mas, sobretudo o fato de articulá-lo a S2 o que produz sentido e, em consequência, alienação.

Diante disso a alienação se define por uma escolha, A liberdade ou a vida? Se alienar ao Outro, detentor do código, e ser um escravo da linguagem, ou não 
alienar? Se a escolha é a liberdade, se perdem as duas imediatamente, pois não há vida sem linguagem, se a escolha é a vida, tem a vida amputada da liberdade, pois a linguagem tem uma falta inerente, já que o discurso não pode dar conta de falar de todas as coisas. Qualquer que seja a escolha que se opere, há por consequência $\circ$ desaparecimento de uma das partes (Lacan, 1964/2008).

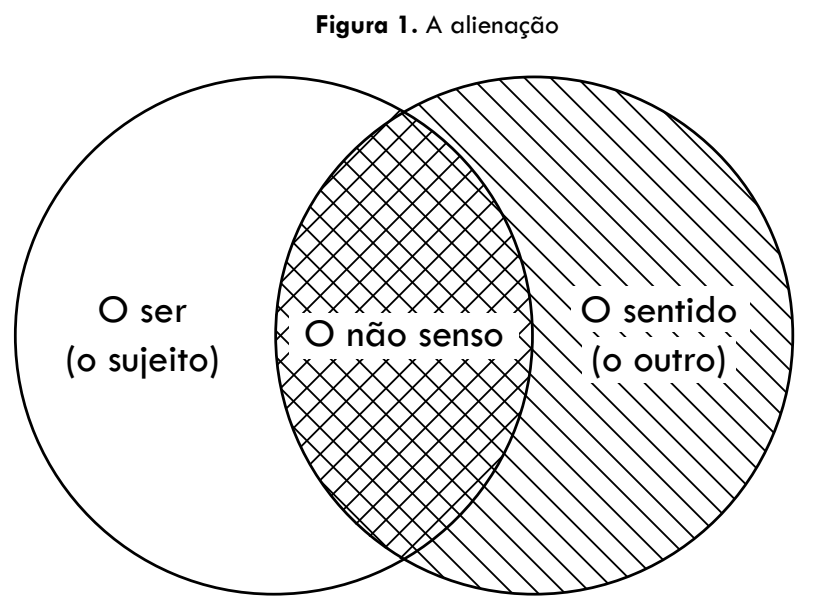

A alienação

Fonte: Adaptação de Lacan, 1985.

Na Figura 1 estão apresentados dois conjuntos, o do ser e do campo do Outro (linguagem/sentido). O elemento que pertence a ambos é o não senso, S1 (Lacan, 1964/2008). Pisetta \& Besset (2011) propõem apreender o não senso como inerente ao sentido, pois nenhum significante recobre o sentido total, não conseguindo dizer quem é o sujeito, sempre falta algo, algum sentido que não pode ser representado por palavras.

Tomar o conjunto do sujeito como vazio antes do encontro com o Outro significa dizer que o sujeito é constituído por meio desse encontro, que o sujeito é fundado a partir dessa nomeação do vazio, dessa "materialização" da ausência. Portanto, o significante é a primeira instância diferenciada, o elemento que retira o ser do real ao delimitá-lo (Nascimento, 2010). Se em alguma parte ele se identifica com um significante (um sentido sobre sua existência), por outro lado ele se situa numa afânise (desaparecimento do sujeito). Assim a definição de seu ser encontra-se sempre parcial, inconsistente e em movimento (Pisetta \& Besset, 2011 ).
Escolhendo apenas a via da alienação, ou seja, do sentido, não seria possível o surgimento do sujeito (\$), pois estaria tomado pelo desejo do Outro. Contudo, sem atravessar, inicialmente essa via, termina-se por cair no sem sentido (non sense) ou no silêncio. Daí a inversão do cogito: eu sou onde eu não penso. Eu penso onde eu não sou (Lacan, 1966/1998). Está aí a condição de sujeito essencialmente dividido, barrado: o fato de que o sujeito enquanto tal não se manifesta senão no intervalo de S1-S2, isto é, antes de o sentido se constituir, mas depois de um significante ter sido capturado. $O$ sujeito se manifesta no inconsciente (onde não penso), pois na consciência, (onde penso) o sujeito se apaga (Nascimento, 2010).

A separação, entretanto, é representada pela intersecção entre os elementos que pertenceriam aos dois conjuntos, o lugar onde se juntariam o sujeito e - Outro, o ser e o sentido. Tal intersecção surge do recobrimento de duas faltas (Lacan, 1964/2008). Uma falta é, pelo sujeito, encontrada no Outro, nos intervalos do discurso do Outro. É a falta do significante onde a linguagem e a via do sentido não conseguem abarcar todo o ser. A outra falta é trazida pelo sujeito que responde a essa captura com a falta, anterior, a sua própria afânise, ao se submeter ao sentido dado pelo Outro (Bruder \& Braver, 2007). Uma falta recobre a outra, é uma dialética dos objetos do desejo, no que ela faz a junção do desejo do sujeito com o desejo do Outro. É a dialética dos processos de alienação e separação, há uma interseção do desejo do Outro que faz aparecer o desejo do sujeito (Lacan, 1964/2008).

No que seu desejo é desconhecido; o sujeito retorna então ao ponto inicial, que é o de sua faltacomo tal. Isso indica que alienação e separação não são "fases" estáticas, e mostra a oscilação permanente que se verifica no analisante entre alienação e separação, como uma alternância sempre renovada

(Bruder \& Braver, 2007, p.519).

Assim não há possibilidade de haver separação, se antes não houver alienação ao Outro. No caso dos autistas os autores discutem haver impasse no processo de alienação, não chegando à operação da separação. É importante destacar que ao estudar estas operações depara-se com a questão da diferenciação entre "eu" e "sujeito", contribuição 
de Lacan que distingue o eu (uma construção imaginária que se estabelece no estádio do espelho) do sujeito do inconsciente (o sujeito do desejo que emerge entre os significantes do discurso).

Assim o objetivo desse estudo é compreender a constituição subjetiva no autismo com base na análise da autobiografia de Temple Grandin sob a luz da teoria lacaniana da alienação e separação, levando em consideração um dos enigmas que percorre esse quadro clínico: constitui-se sujeito no autismo? Diante disso, este trabalho se faz relevante ao abordar questionamentos tão presentes no campo psicanalítico e de fundamental importância para pensar o manejo terapêutico da clínica do autismo.

\section{Metodologia}

Este trabalho constitui uma pesquisa qualitativa, na qual foi realizada uma análise documental do livro "Uma menina estranha: Autobiografia de uma autista" que traz o relato autobiográfico de Temple Grandin, uma autista que influenciou a visão do autismo e seus tratamentos. A análise do documento foi realizada com base na teoria da alienação e separação, exposta no primeiro ensino de Lacan proposta no Seminário 11. Neste seminário, ao abordar o que Lacan nomeia como os quatro conceitos fundamentais da psicanálise (inconsciente, pulsão, repetição e transferência), ele elabora os conceitos de alienação e separação como intrínsecos ao processo de constituição do sujeito.

Teoria esta que é apresentada nos trabalhos de alguns autores (Catão, 2015; Freire, 2002; Jerusalinsky, 2012 e 2015; Laznik, 2013 e 2015; Maleval, 2012, 2015 e 2017; Soler, 1999 e 2007; Stefan, 1991) os quais, na presente pesquisa, foram utilizados como base para discussão dos elementos presentes na obra analisada.

\section{Análise da autobiografia de Temple Grandin}

Diante da questão levantada, eis a análise do livro "Uma menina estranha: autobiografia de uma autista" que retrata a autobiografia de Temple Grandin, engenheira e bióloga, que bem cedo foi diagnosticada com autismo. Até os três anos e meio, Temple só reagia ao seu entorno por intermédio de gritos, assobios e murmúrios de boca fechada. Sua mãe percebeu que já aos seis meses ela não se aninhava no colo: ficava rígida, rejeitava o corpo que queria abraçá-la. Na escola, batia na cabeça das outras crianças. Em vez de argila ou massinha sintética, usava as próprias fezes para modelar e espalhava suas criações pelo quarto.

Temple Grandin foi estimulada precoce e intensivamente pela mãe e posteriormente conduzida à escola onde é auxiliada por um sensível professor até a conclusão do ensino médio, quando se muda para a fazenda de sua tia. Nesse contexto inicia seu interesse por bovinos ao observar e compreender de forma peculiar os comportamentos desses animais, especialmente a forma como eles se mostram calmos ao serem imobilizados para receberem vacinas. A partir dessa experiência, idealiza e constrói um dispositivo semelhante que a pressiona e imobiliza, gerando uma sensação de tranquilidade que aplaca as crises de ansiedade decorrentes da sua inabilidade no relacionamento social, o que foi chamado por ela de "máquina do abraço".

Seus familiares percebem suas notáveis habilidades, ao que é pressionada para seguir os estudos na universidade, iniciando uma trajetória marcada por intensas dificuldades no ambiente acadêmico. Seu modo diferenciado de ver e entender o mundo a obriga a desenvolver estratégias para superar obstáculos até concluir seu $\mathrm{PhD}$ em engenharia agropecuária, quando revoluciona os métodos de manejo do gado e torna-se uma respeitada especialista no assunto.

É importante ressaltar que Temple traz na sua autobiografia uma visão do autismo embasada na neurociência e na terapêutica comportamental. Assim são antecipadas ao leitor as limitações dessa análise, que não se tem o objetivo de esgotar as reflexões e hipóteses a respeito da relação do autismo e os processos alienação e separação, mas suscitar olhares psicanalíticos sobre esse quadro clínico.

Partindo para a análise do livro, logo na capa é notório o nome de duas autoras, além de Temple Grandin, obviamente por se tratar de sua 
autobiografia, tem-se o nome de Margaret Scariano autora americana. Esse fato suscita a observação de Maleval (2015) de que não é raro que os escritos dos autistas sejam redigidos "a duas vozes", o autor se apoiando em uma pessoa de seu meio para conseguir conduzir bem seu trabalho de escrita. $O$ que já suscita a dificuldade dos autistas com os códigos da linguagem.

Logo no início da autobiografia Temple Grandin define o autismo como um distúrbio do desenvolvimento; uma deficiência nos sistemas que processam a informação sensorial recebida, o que faz a criança reagir a alguns estímulos de maneira excessiva, enquanto a outros reage debilmente. Ela levanta a discussão das possíveis causas neuropsicológicas do autismo, e coloca este como um mistério.

Muitas vezes, a criança se "ausenta" do ambiente que a cerca e das pessoas circunstantes a fim de bloquear os estímulos externos que lhe parecem avassaladores (Grandin, 2012, p. 18). [...] Esses sintomas parecem surgir nos primeiros meses de vida. $O$ bebê não responde da mesma forma que os demais. Não é surdo, pois reage aos sons. Mas suas reações a outros estímulos sensoriais são inconscientes. [...] Outros sintomas do autismo são esquivar-se ao toque alheio, ausência de fala com significado, comportamentos repetitivos [...] e falta de contato emocional com as outras pessoas (Grandin, 2012, p. 19).

Grandin (2012) relata que já era adulta a primeira vez que conseguiu olhar alguém nos olhos: "Quando era criança, lembro minha mãe dizendo: 'Temple, está me ouvindo? Olhe para mim'. Às vezes eu tentava, mas não conseguia... E havia outros sinais indicadores. Eu me interessava pouco pelas outras crianças, preferindo meu mundo interior" (p. 28).

A teoria de Laznik (2013) aponta esses comportamentos no autismo como decorrente a um fracasso da alienação na constituição do sujeito; e isso, entre outros, pela impossibilidade ou recusa do remate do terceiro tempo do percurso pulsional, que é nomeado de passivo, onde o bebê se faz ele mesmo objeto de um Outro. $O$ primeiro e segundo tempos são respectivamente, 0 chamado ativo quando o bebê vai em busca de um objeto externo e o tempo reflexivo quando o bebê toma como objeto uma parte do seu próprio corpo. Assim sem o fechamento do circuito pulsional se tem o fracasso da instauração da alienação do bebê na relação do Outro, o que explicaria a impossibilidade do retorno de voz e olhar de Temple Grandin para sua mãe, já que não é possível se articular a um Outro real.

Em outro momento Laznik (2015) reafirma tal teoria, apontando que a falha no autismo ocorre no processo de alienação, diferente do psicótico que a falha é no processo de separação, onde tal distinção é possível a partir do Seminário 11 de Lacan. Corroborando com esta teoria, Catão (2015) aponta a existência de um funcionamento psíquico particular na criança autista, onde sua posição subjetiva é de recusa radical e precoce do que vem do campo do Outro. E esta recusa pode ser observada nos registros pulsionais; oral, controle esfincteriano, olhar e voz.

Catão (2015) ainda levanta a hipótese de que no autismo há um comprometimento da identificação primária, pelo viés da recusa da voz. Assim a marca deixada pelo encontro com o significante não se ordena em cadeia e o sujeito não entra no discurso. A autora vai apontar que o autista se coloca à margem do campo da linguagem. Isso explicaria a ausência ou baixa presença de vocalizações e balbucios, endereçados ao Outro e a recusa a voz do Outro, exemplificado no recorte do autorrelato de Temple Grandin.

Jerusalinsky (2012) vai de encontro às autoras citadas ao suscitar que no autismo não se constituiu sujeito, se apresenta uma ausência de sujeito, já que falta a demanda de reconhecimento do Outro e o desejo do desejo do outro para que seja possível considerar uma estrutura mínima de sujeito. $O$ autista estaria fora da linguagem, na medida em que 0 inconsciente do sujeito se estrutura como linguagem. E a prevalência de automatismos cria um mecanismo de exclusão da criança a respeito da linguagem. Por isso os autistas desviam seu olhar do outro semelhante e se fazem de surdos não a qualquer som, mas especificamente ao outro falante. Nesse sentido o autor suscita o movimento terapêutico de supor um sujeito precisamente aí onde não há tal.

Em outra oportunidade Jerusalinsky (2015) aborda que no autismo registra-se um ponto de falha precoce comum a todos, falha esta caracterizada como a quebra ou descontinuidade no reconhecimento 
recíproco entre o filho e sua mãe (ou cuidadora). Esse desencontro segundo o autor é a chave para a instalação da criança numa posição autística, que se constitui por não possuir representação do outro e por isso rechaça sua relação com ele. E quando por um acaso há relação, essa é episódica, fugaz, descontextualizada, mínima e de nenhuma ou escassa extensão imaginária e de nula extensão simbólica.

Outros autores concordam ao apontar que a ausência de contato pelo olhar e a falta ou a raridade do sorriso social no autismo, é uma recusa do autista a ceder ao Outro os objetos pulsionais (Maleval, 2015). Freire (2002) aponta que no autismo a criança não responde a Outro constituinte e Soler (1999) afirma que as crianças autistas buscam a anulação do Outro, porque se sentem invadidas pela presença deste. Há recusa e evitação do olhar e da voz. A criança parece não estar ouvindo ou olhando. Por isso também, a criança exibe uma rejeição da palavra do Outro, como, por exemplo, no ato de tapar os ouvidos.

Grandin (2012) relata que até começar a falar, a comunicação para ela era uma via de mão única. Ela se refere que entendia o que diziam, mas era incapaz de responder. Assim, berrar e bater os braços eram sua única forma de comunicação. Mesmo quando começou a falar, ora estava no discurso ora não. "As pessoas a minha volta não sabiam explicar por que às vezes eu conseguia falar e outras vezes não" (Grandin, 2012, p. 24).

A sua primeira palavra pronunciada foi "gelo", quando ela tinha três anos, em um acidente de carro, o vidro da janela estilhaçou e caiu sobre ela, o que a fez associar os cacos de vidro a gelo. Esse fato suscita a hipótese de Maleval (2015) de que o autista não está exilado da linguagem, que a retenção da voz se revela na estranheza da enunciação dos autistas, onde há quatro maneiras bem diferentes de lidar com a fala.

A mais radical é a de recusá-la, que expressa o mutismo obstinado de um grande número de autistas. Outra via é os autistas que explicitam adorar "o som de sua própria voz". Há ainda a verborréia que quase não permite a comunicação, eles recorrem a uma linguagem factual, sem cessão da voz, que confere o tom monocórdio surpreendente dos autistas de alto nível. Por fim, existe uma maneira mais rara de comunicar, as impressionantes frases espontâneas que escapam desses sujeitos mudos nos momentos de angústia, exemplo apresentado por Grandin (2012). Quando isso ocorre, a retenção da voz cessa por um instante. É frequente a constatação de que autistas mudos saem, às vezes, de seu silêncio, pronunciando uma frase perfeitamente construída, antes de retornarem ao seu mutismo (Maleval, 2015).

É característico que isso se produza quase sempre em situações críticas que extravasam as estratégias protetoras do sujeito, fazendo-o abandonar, por um instante, a recusa em convocar o Outro e a recusa em inscrever a voz na fala (Maleval, 2017).

Essas estratégias aparecem na autobiografia de Grandin (2012) ao ponderar que mesmo após verbalizar ela apresentava uma dificuldade em falar dos seus sentimentos, sem apresentar entonação e inflexão na voz, uma maneira mecânica de falar. $O$ que corrobora com Maleval (2012; 2015) que diz que na impossibilidade de se alienar completamente na linguagem, uma das estratégias criadas pelos autistas para contorná-la, seria a preservação de uma voz centrífuga, situação na qual preferiria ouvir seus próprios ruídos em detrimento àqueles do Outro. $O$ autor ainda ressalta que as raras circunstâncias nas quais o autista engaja a sua voz enunciativa vêm confirmar, pela sua não assunção, que ele resiste à alienação de seu ser na linguagem retendo o objeto de gozo vocal. Onde esses fenômenos sugerem fortemente que o autista se enraíza não num déficit cognitivo, mas numa escolha imponderável do ser, a fim de se proteger da angústia.

Assim também a hipótese de Freire (2002) abarca que as estereotipias e ecolalias seriam recursos de manobra em face da iniciativa insuportável do Outro. Trata-se de tentativas, talvez, no real, de inscrever uma diferença, mínima que seja, entre o eu e o que vem do outro. Diferente da significância, aonde no efeito de retroação uma significação de forma invertida, vinda do outro, faz o sujeito se representar entre dois significantes; os gestos "estereotipados" e palavras "ecolálicas" dos autistas não parecem apresentar uma mensagem de forma invertida que possam identificá-los em apelo. 
Assim o autismo se apresenta como um enigma uma vez que coloca o seguinte impasse: como diante da alteridade própria a estrutura da linguagem, um sujeito "responde" não, reconhecendo a linguagem como tal, mas se mostrando alheio à alteridade própria do campo do Outro? Como um sujeito pode se apresentar rejeitando, ou tentando anular a dimensão do outro desde o momento que é introduzido a partir do objeto - objeto como o que designa a não-unidade entre o eu e o outro - anulação esta que implica na própria anulação do sujeito como alteridade a esse objeto? (Freire, 2002).

Diante dessas teorias que apontam no autismo um movimento ativo de recusa ao Outro, pode-se pensar na presença de um sujeito, mesmo não existindo necessariamente o discurso?

Tal questionamento também é apresentado por Soler (2007) que afirma que o infans já está imerso na linguagem antes mesmo de poder falar. Portanto, ela acredita que os autistas estão na linguagem, mesmo que não falem, sendo sujeitos, na medida em que elas são faladas; no Outro, há significantes que as representam. Assim os autistas estariam no aquém da alienação, sendo estes sujeitos, mas não enunciadores, aparecendo como puro significado do Outro:

Assim, podemos fazer a notação do sujeito autista segundo a primeira forma: $s$ - sujeito - representado, suposto, colocado sob os significantes que o representam no Outro: S/s. Essa é, aliás, a primeira emergência de qualquer sujeito, seja ele quem for. A pergunta formulada por Lacan no Seminário 11 e em "Posição do inconsciente" é de que modo esse sujeito, definido como puro efeito, falado pelo Outro,

pode virar agente, tornar-se alguém que fala que deseja, ou, em outras palavras, alguém movido pela libido. A fórmula $S / s$ escreve, inicialmente, o sujeito suposto pelos significantes do Outro, e que ainda não

"[fez] sua entrada no real". Nesse momento, é no máximo a libido do Outro que se liga a ele, a tal ponto que poderíamos evocar sua inclusão no lugar do Outro.(Soler, 2007, p. 67).

Segundo os professores de Temple, ela falava de maneira estranha e fazia perguntas muito esquisitas, repetindo a mesma pergunta várias vezes, sendo nomeada com o apelido de vitrola. "minha voz era inexpressiva, com pouca inflexão e nenhum ritmo" (Grandin, 2012, p. 28).

O que suscita a hipótese de Stefan (1991) que discute que a criança autista pode falar, mas esse não é um ato que produz laço social, e, portanto, não produz discurso. Essas crianças falam, mas não se dirigem a ninguém, e suas falas não as enlaçam a ninguém. $\bigcirc$ que explicaria a inflexão na voz.

Isso porque em contrapartida a teoria de Soler (2007); Stefan (1991) aborda o autismo em um tempo anterior ao estádio do espelho, afirmando que no autismo não haveria Outro e sequer o outro, o semelhante. Este autor afirma a ausência de laço das crianças autistas a partir da constatação de que não estão constituídas na e pela linguagem: estão fora do discurso e fora da linguagem. Se o sujeito é uma produção, um efeito do fato de que somos seres de linguagem, então o autista está fora da linguagem nessa acepção estrita do termo. Nos bebês, a não constituição do laço é atestada pela ausência de olhar, de vocalizações. Se for pela e na linguagem que se constitui o sujeito, seria necessário falar, no caso do autista, de uma ausência de subjetivação. Em concordância, Laznik (2013, p. 65) afirma:

Parece-me agora possível fazer a hipótese que nos autistas ocorre um fracasso do tempo de alienação da constituição do sujeito; e isso, entre outros, pela impossibilidade ou recusa do remate do terceiro tempo do percurso pulsional - tempo onde o Ich se faz objeto de um novo sujeito. Esta hipótese poderia certamente dar conta do fato que se constata às vezes neles uma linguagem que não se encarna, e que parece depender de uma tomada num Outro simbólico-puro código, sem poder se articular a um Outro real que poderia encarná-lo, sem que exista tampouco no mesmo movimento acesso ao estágio do espelho e à constituição de um eu e à alienação imaginária que esta instância comporta.

Em consonância com Laznik (2013) quando cita o estádio do espelho, Jerusalinsky (2012) aponta que - autismo consiste na ausência do imaginário e simbólico, decorrente do espelho que o intermediário materno oferece à criança a devolver permanentemente à esfera do Real, seja por uma impossibilidade psíquica de sustentar um lugar de circulação simbólica a esse filho, seja porque o filho está 
organicamente impedido de chegar a se constituir como sujeito ou pela combinação dos dois fatores.

O estádio do espelho é assim chamado porque cada semelhante (os outros) passam a funcionar como um espelho à criança, que então contempla os efeitos que a sua voz, gestualidade e expressões causam no outro. Assim esse estádio tem a 'função de reconhecimento' que tem um valor fundamental em ser a porta de entrada ao campo da linguagem. No autismo observa-se a existência de um obstáculo intransponível entre a criança e seu Outro Primordial, - que culmina no fracasso dessa função primordial de reconhecimento (Jerusalinsky, 2012).

Mexko e Galhardi (2014) corroboram da hipótese de Laznik (2013) de que no autismo, o terceiro tempo do circuito pulsional não se fecha. Sem existir - circuito pulsional completo, o corpo não é tomado pela pulsão, não se constrói erógeno, os orifícios corporais não fazem borda. Não havendo o estabelecimento desse laço do bebê com seu Outro primordial, ele não pode advir como sujeito da pulsão.

Em contrapartida Maleval (2015) aponta que - autismo não permaneceu fora ou na borda da alienação; ele está na alienação, mas a recusa. A alienação significante não é assumida pelo autista, ocorreria o que Maleval (2012) nomeia de alienação parcial. Não há afânise do sujeito; a linguagem faz, em contrapartida, eco em seu corpo. Aquele que comunica sem engajar a voz. E esta é a dificuldade com a qual os autistas de alto nível são confrontados, e eles a resolvem por meio da língua factual. Que é o que Grandin (2012) se referiu ao descrever a fala estranha, inexpressiva, com pouca inflexão e nenhum ritmo. Segundo Maleval (2015) é uma fala como se fosse um acúmulo de fatos, de acontecimentos, de nomes e de datas.

As palavras são mais emitidas do que faladas, já que estas falas provêm de um repertório mental memorizado. E quando há uma fixação em um assunto, 0 entusiasmo thes inspira um discurso verborrágico, chegando a uma verborréia incessante (Maleval, 2017).

"Como muitas crianças autistas, tudo para mim era literal" (Grandin, 2012, p. 83). "Meus pais não entendiam minha lógica, e eu, sendo uma pessoa que pensava por imagens, não entendia a deles"
(Grandin, 2012, p. 85). "As sutilezas da linguagem me escapava" (Grandin, 2012, p.34). "Eu pensava visualmente, e precisava de símbolos concretos para conceitos abstratos" (Grandin, 2012, p.84). Esses autorrelatos suscitam a teoria de Soler (1999) de que no autismo o significante terá valor de signo, ao qual corresponderá a apenas um significado.

A teoria de Soler (1999) é apresentada pelas autoras Kupfer, Faria \& Keiko (2007, p. 159) ao afirmar que:

Há de início um $S 1$ que representa a criança no campo do Outro. O problema é que a partir desse primeiro significante, engendrado no campo do Outro, não se seguirão outros. $E$ um significante isolado não pode ser considerado como tal, na medida em que seu significado não será gerado pelo deslizamento e pelas possibilidades de combinação e de substituição com outros significantes, o que é próprio do funcionamento da linguagem. Assim o significante terá apenas valor de signo. Se o Outro está fixado a um só significado, ficará sempre no mesmo lugar: no do Outro absoluto.

Não há então o que perguntar sobre o desejo do

Outro, não há dialetização, dúvida (o que quer o Outro de mim?). Por isso o Outro se torna absoluto, não recortado, não simbolizado. Assim a presença do Outro será sígnica. Isto quer dizer que a criança não opera com a polissemia, a variabilidade, a incerteza.

O Outro terá significados fixos, sempre sígnicos. As variações serão vistas como um problema, e a elas a criança reagirá evitando-as. [...] Por essa razão, as crianças comportam-se como se fossem perseguidas pelos signos de presença do Outro, que é intrusiva.

Reagem a tudo que é imprevisível como sinal de presença do Outro, buscando anulá-lo.

Maleval (2015) vai de encontro à teoria de Soler (1999) quando o autor aponta que o uso do significante se encontra apagado em proveito do signo. Ele diz que o ideal para os autistas "seria um código que conseguiria conectar as palavras de forma constante e rígida aos objetos ou a situações claramente determinadas" (p. 22). O problema não está na complexidade da língua, pelo contrário quanto maior for sua complexidade, menor o risco de uma palavra ser polissêmica. "Quanto mais regras e estruturas, menos o autista deve se apoiar em sua intuição e no contexto. O ideal seria um sentido para uma palavra, uma língua que se reduzisse a um código, totalmente construída com signos" (Maleval 2015, p. 22). 
Para o autista, a linguagem não faz inexistir aquilo de que se fala; a palavra não é totalmente a morte da coisa. É difícil no autista o descolamento do significante e do objeto, que é o que permite à criança fingir que um sapato é um carro, por exemplo. Todavia, Maleval (2015) afirma ser abusivo dizer que os autistas não têm acesso à abstração. Apesar de suas capacidades de simbolização passarem basicamente pelo índice, e mesmo pelo ícone, elas colocam em ação um processo de substituição que lhes permitem levar a coisa à linguagem.

As crianças autistas também costumam gostar de rotina, como Temple que se dedicava a formular um conjunto de regras praticáveis que dessem conta de seu comportamento e da conduta dos outros, "o mundo ao qual tentam desesperadamente impor alguma ordem" (Grandin, 2012, p. 21). "Novos lugares me deixavam perturbada" (Grandin, 2012, p. 34).

O que é apontado por Maleval (2015) que afirma que nos autistas a adaptação ocorre por meio do intelecto, da explicação racional das coisas. "O autista gostaria que o mundo das coisas fosse regido por regularidades fixas; ele sofre com o fato de que a realidade flutue em função das interpretações subjetivas. A ambiguidade significante o desorienta; ele busca codificar o mundo com a ajuda de signos." (p. 26).

Jerusalinsky (2012) também fala desse aspecto ao mencionar que a presença do Outro é intrusiva para a criança autista, sendo seu mecanismo de defesa a exclusão. Entretanto para esse autor a exclusão deixa o autista fora da linguagem e do processo de alienação, divergindo de Maleval (2015) que, como já mencionado, acredita que o autista está dentro da linguagem, em uma alienação parcial.

Assim é por intermédio de objetos que os autistas podem abrir-se para 0 mundo, esse objeto foi nomeado por Tustin em 1972, como objeto autístico. $O$ objeto autístico está no princípio das defesas do autista que consistem essencialmente, em manter o controle e colocar-se fora do alcance (Maleval, 2015). O objeto autístico se interpõe entre o sujeito e o desejo do Outro possibilitando ao autista colocar uma barreira frente ao mundo. Entretanto, se o autista puder manter o controle de seu objeto autístico, poderá por seu intermédio estabelecer uma relação com o mundo.
Essa análise lembra a máquina do abraço de Temple Grandin, que desde sua construção facilitou a conexão da mesma com o mundo. Essa máquina sob o controle de Temple a possibilitava ter algo em contato com seu corpo, uma espécie de contenção corporal, que a acalmava. Com relação à máquina do abraço, temos as seguintes afirmações de Grandin (2012):

Porém, o que era mais importante para uma pessoa autista, era eu quem exercia o controle ao contrário da situação em que era engolida pelo excesso de afeição da minha tia (p. 93). Quando entrava no brete, sentia-me mais próxima de pessoas como a minha mãe, - Sr. Peters, o Sr. Brooks, O Sr. Carlock e a tia Ann. Embora fosse apenas um aparelho mecânico, o brete derrubou minha defensividade táctil, e eu podia sentir - afeto e a preocupação das pessoas, conseguindo exprimir meus sentimentos por mim mesma e pelos outros. Era como se uma porta pantográfica tivesse sido aberta, revelando minhas emoções (p. 97).

Maleval (2015) também destaca na clínica do autismo uma aptidão desses sujeitos para desenvolverem o que se nomeia como "interesses específicos". As competências que eles adquirem nesse campo às vezes se generalizam, chegando a lhes permitir uma inserção profissional. $O$ que é observado na autobiografia de Temple Grandin, no seu intenso interesse pelos comportamentos bovinos e sua inserção profissional nesse campo.

A atração por um interesse específico pode incitar - autista a uma aquisição espontânea de competências sociais, que o levam a desenvolver, a partir dele mesmo, seu Outro de síntese. Os objetos autísticos e os interesses específicos servem de proteção contra o desejo do Outro, a recusa da alienação, evita se confrontar com a angústia, dinamizam o sujeito e, às vezes, permitem avançar na vida social (Maleval, 2015).

Como é apresentado na autobiografia de Temple Grandin que ao longo dos anos foi expandindo suas habilidades sociais, sua comunicação e a expressão na voz; como o professor de Temple relata: "O tom da sua voz melhorou. Não está mais tão inexpressivo" (Grandin, 2012, p.90). O que culmina a análise de que a "máquina do abraço" e o seu interesse específico por bovinos, não distanciou Temple Grandin do mundo, mas pelo contrário, a permitiu 
uma inserção no mundo e uma relação com o outro de modo menos invasivo para a mesma.

\section{Considerações finais}

Diante da análise da autobiografia de Temple Grandin com base em teorias psicanalíticas sobre o autismo e tomando como bússola norteadora a teoria da alienação e separação de Lacan; foi possível perceber que apesar de cada autor destinar seu olhar para distintos aspectos dentro do autismo, eles convergem em alguns aspectos. Primeiro de que todos abordam o autismo diferenciando das outras estruturas psíquicas; neurose, psicose e perversão. $E$ que estes convergem na concepção de que na estruturação subjetiva da criança autista, o cerne da questão ocorre no processo da alienação, sendo possível observar sinais do autismo desde a primeira infância, na interface da relação da criança com o Outro, o campo da linguagem.

Ao mesmo tempo percebem-se divergências nas teorias. Onde Laznik, Jerusalinsky, Catão e Stefan apontam que há um fracasso na alienação e em decorrência deste fracasso não há constituição do estádio do espelho e não advém o sujeito, pois o autista está fora da linguagem. De outro lado Soler, Freire e Maleval corroboram que o autista não está fora da linguagem, considerando que os seres humanos estão na linguagem antes mesmo de nascer, pois são falados pelo Outro.

Entretanto destaca-se que Soler fala de um aquém da alienação, enquanto Maleval posiciona o autismo não estando aquém da alienação, mas na alienação, em uma posição ativa de recusa ao Outro. $E$ assim estando o autista inserido na linguagem e sendo possível o laço social por meio dos objetos autísticos e interesses específicos, poderia se pensar no que ele chamou de alienação parcial.

Diante dessa análise percebe-se que não há uma teoria que dê conta de explicar toda a complexidade do autismo, mas a que se apresenta como mais interessante para pensar o caso de Temple Grandin é a leitura de Maleval (2012, 2015 e 2017) que traz a alienação parcial, onde a criança autista ora está no discurso ora não está. $\bigcirc$ que é percebido durante toda autobiografia de Temple Grandin, na dificuldade de se inserir no discurso por meio da fala, voz, expressões, entonação e de se articular pela via especular ao outro.

Foi percebido com essa pesquisa que a teoria da alienação e separação tem limitações já que ao falar de autismo requer que se pensem também os conceitos de gozo, pulsão, como também possa avançar no segundo ensino de Lacan, onde emerge o significante: lalíngua. Assim é de suma importância o avanço nos ensinos lacanianos para se pensar essa clínica de uma perspectiva mais ampla, respeitando sua complexidade.

Também foi possível observar que não há uma resposta para o enigma da constituição subjetiva no autismo. Pois se ao falar de sujeito, estiver se referindo ao sujeito barrado (\$), do neurótico, esse não advém no autismo, como também não se constitui na psicose. Mas nem por isso, a psicanálise deixou de considerar o psicótico como sujeito. De tal modo, porque não pensar que no autismo há um sujeito em constituição, um sujeito a vir a ser, com um funcionamento particular, distinto das outras estruturas (neurose, psicose e perversão)?

São questionamentos que inquietam e movem os pesquisadores que permeiam a clínica do autismo, o qual relança o enigma da constituição do sujeito e faz o analista trabalhar e com isso a psicanálise avançar. Assim esse trabalho não teve como objetivo esgotar as discussões e análises sobre ao autismo, mas discutir algumas hipóteses e leituras desse quadro clínico, que tem sido cada vez mais abordado nas pesquisas e clínicas, mas ainda levanta muitos questionamentos aos profissionais da saúde.

\section{Contribuições das autoras}

Borges, M. Y. P. participou do levantamento dos textos da revisão da literatura, sistematização dos dados e confecção das análises e da redação do manuscrito. Castro, M. L. S. orientou a condução do trabalho, além de contribuir com a redação e revisão do manuscrito final.

\section{Conflitos de interesses}

Nenhum conflito financeiro, legal ou político envolvendo terceiros (governo, empresas e fundações privadas, etc.) foi declarado para nenhum aspecto do trabalho submetido (incluindo mas não limitandose a subvenções e financiamentos, participação em conselho consultivo, desenho de estudo, preparação de manuscrito, análise estatística, etc.). 


\section{Referências}

American Psychiatric Association. (2000). Manual Diagnóstico e Estatístico de Transtornos Mentais - DSM 4 (4a ed.). Porto Alegre: Armed.

American Psychiatric Association. (2014). Manual Diagnóstico e Estatístico de Transtornos Mentais - DSM 5 (5a ed.). Porto Alegre: Armed.

Bruder, M. C. R., \& Braver, J. F. (2007). A constituição do sujeito na psicanálise lacaniana: impasses na separação. Psicologia em Estudo, 12 (3), 513-521. doi: $10.1590 /$ S1 $413-73722007000300008$

Catão, I. (2015). A linguagem como mistério não revelado: voz e identificação nos autismos. In: A. Jerusalinsky (Org.), Dossiê autismo. São Paulo: Instituto Langage.

Dias, S. (2015). Asperger e sua síndrome em 1944 e na atualidade. Revista latino-americana de psicopatologia fundamental, 18(2), 307-313. doi: $10.1590 / 1415-4714.2015 v 18 n 2 p 307.9$

Figueiredo, A. C., \& Machado, O. M. R. (2000). O diagnóstico em psicanálise: do fenômeno à estrutura. Ágora: Estudos em Teoria Psicanalítica,3(2), 65-86. doi: $10.1590 /$ S1516-14982000000200004

Freire, A. B. (2002). O diagnóstico em psicanálise: do fenômeno à estrutura. Estilos da clínica, 7(13), 65-86. doi: $10.1590 /$ S1516-14982000000200004

Grandin, T., \& Scariano, M. M. (2012). Uma menina estranha: autobiografia de uma autista (S. Flaksman, Trad.). São Paulo: Companhia das Letras.

Jerusalinsky, A. (2012). Psicanálise do autismo (2a ed.) São Paulo: Instituto Langage.

Jerusalinsky, A. (Org.). (2015). Dossiê autismo. São Paulo: Instituto Langage.

Kanner L. (1943). Autistic disturbances of affective contact. Nervous Child, (2), 217-50.

Klin, A. (2006). Autismo e síndrome de Asperger: uma visão geral. Revista Brasileira de Psiquiatria, 28(Supl I).

Kupfer, M. C. M.; Faria, C., \& Keiko, C. (2007). O tratamento institucional do Outro na psicose infantil e no autismo. Arquivos Brasileiros de Psicologia, 59(2), 156-166.

Lacan, J. (1985). O seminário o livro 11 : os quatros conceitos fundamentais da psicanálise (2a. ed.). Rio de Janeiro: Zahar.
Laurent, É. (1997). Alienação separação I. In: Feldstein, R., Fink, B. \& Jaanus, M. (Orgs.). Para ler o seminário 11 de Lacan: os quatro conceitos fundamentais da psicanálise (pp. 31-41). Rio de Janeiro: Zahar.

Laurent, É. (1997). Alienação separação II. In: Feldstein, R., Fink, B. \& Jaanus, M. (Orgs.). Para ler o seminário 11 de Lacan: os quatro conceitos fundamentais da psicanálise. (pp. 41-51). Rio de Janeiro, Zahar.

Laznik, M. C. (2013). A voz da sereia: o autismo e os impasses na constituição do sujeito. Salvador: Ágalma.

Laznik, M. C. (2015). Diversos olhares sobre o autismo. In: Jerusalinsky, A. (Org.). Dossiê autismo. São Paulo: Instituto Langage.

Lüdke, M., \& André, M. E. D. A. (1986). A pesquisa em educação: abordagens qualitativas. São Paulo: EPU.

Maleval, J. C. (2012). Língua verbosa, língua factual e frases espontâneas nos autistas. In: Murta, A., Calmon, A., \& Rosa, M. (Orgs.). Autismo(s) e atualidade: uma leitura lacaniana. Belo Horizonte: Scriptum.

Maleval, J. (2015). Por que a hipótese de uma estrutura autística? Opção Lacaniana online, 6(18).

Maleval, J. C. (2017). O autista e a sua voz. São Paulo: Blucher.

Mexko, S., \& Galhardi, C. M. (2014). Autismo Infantil: revisão de literatura a partir da psicanálise lacaniana. Psicologia Argumento, 32(77), 129-136. doi: $10.7213 /$ psicol.argum.32.077.AO06

Nascimento, M. B. (2010). Alienação, separação e travessia da fantasia. Opção Lacaniana online, 1(1).

Pisetta, M. A. M. \& Besset, V. L. (2011). Alienação e separação: elementos para discussão de um caso clínico. Psicologia em Estudo, 16(2), 317-324.

Soler, C. (1999). Autismo e paranóia. In: Alberti, S. (Org.). Autismo e esquizofrenia na clínica da esquize. Rio de Janeiro: Contra Capa.

Soler, C. (2007). O inconsciente a céu aberto da psicose. Rio de Janeiro: Zahar.

Stefan, D. R. (1991) Autismo e psicose. In: Laznik-Penot, M. C. (Org.). O que a clínica do autismo pode ensinar aos psicanalistas. Salvador: Ágalma.

Tendlarz, S. E. (2017). Lacan e o autismo em nossa época. Opção Lacaniana online, $8(23)$.

Lacan, J. (1998). Escritos. Rio de Janeiro: Zahar. 